\title{
Building a Citizen Pscientist: Advancing Patient- Centered Psoriasis Research by Empowering Patients as Contributors and Analysts
}

\author{
Isabelle M. Sanchez · Lindsey Shankle · Marilyn T. Wan · Ladan Afifi · Jashin J. Wu • Frank Doris • \\ Alisha Bridges · Marc Boas · Brian Lafoy · Sarah Truman · Ana-Maria Orbai · Junko Takeshita • \\ Joel M. Gelfand · April W. Armstrong · Michael P. Siegel · Wilson Liao
}

Received: March 22, 2018 / Published online: June 6, 2018

(C) The Author(s) 2018

\section{ABSTRACT}

Introduction: To design and implement a novel cloud-based digital platform that allows psoriatic patients and researchers to engage in the research process.

Methods: Citizen Pscientist (CP) was created by the National Psoriasis Foundation (NPF) to support and educate the global psoriatic disease community, where patients and researchers have the ability to analyze data. Psoriatic patients were invited to enroll in CP and contribute health data to a cloud database by responding to a 59-question online survey. They were then invited to perform their own

Enhanced digital features To view enhanced digital features for this article go to https://doi.org/10.6084/ m9.figshare.6269294.

I. M. Sanchez · L. Afifi · W. Liao ( $\square)$

Department of Dermatology, University of

California San Francisco, San Francisco, USA

e-mail: wilson.liao@ucsf.edu

L. Shankle · M. P. Siegel

National Psoriasis Foundation, Portland, USA

M. T. Wan · J. Takeshita · J. M. Gelfand

Department of Dermatology, University of

Pennsylvania, Philadelphia, USA

J. J. Wu

Department of Dermatology, Kaiser Permanente Los

Angeles Medical Center, Los Angeles, USA analyses of the data using built-in visualization tools allowing for the creation of "discovery charts." These charts were posted on the CP website allowing for further discussion.

Results: As of May 2017, 3534 patients have enrolled in CP and have collectively contributed over 200,000 data points on their health status. Patients posted 70 discovery charts, generating 209 discussion comments.

Conclusion: With the growing influence of the internet and technology in society, medical research can be enhanced by crowdsourcing and online patient portals. Patient discovery charts focused on the topics of psoriatic disease demographics, clinical features, environmental triggers, and quality of life. Patients noted that the $\mathrm{CP}$ platform adds to their well-being and allows them to express what research questions

L. Shankle $\cdot$ M. T. Wan $\cdot$ L. Afifi · J. J. Wu

F. Doris - A. Bridges - M. Boas - B. Lafoy ·

S. Truman - A.-M. Orbai - J. Takeshita .

J. M. Gelfand · A. W. Armstrong .

M. P. Siegel · W. Liao

Citizen Pscientist Governance Council, National

Psoriasis Foundation, Portland, USA

A.-M. Orbai

Division of Rheumatology, Johns Hopkins

University School of Medicine, Baltimore, USA 
matter most to them in a direct and quantifiable way. The implementation of CP is a successful and novel method of allowing patients to engage in research. Thus, CP is an important tool to promote patient-centered psoriatic disease research.

Keywords: Clinical research; Digital; Psoriasis; Internet; Patient-reported outcomes; Online; Portal; Psoriatic arthritis; Quality of life; Symptoms

\section{INTRODUCTION}

Psoriasis is a common chronic autoimmune and inflammatory disease that affects the skin and causes a significant impact on quality of life, affecting approximately $2-4 \%$ of the US population [1, 2]. It is characterized by sharply demarcated, scaly, and erythematous skin lesions most commonly affecting the scalp, elbows, knees, feet, and trunk. Psoriatic arthritis (PsA), depression, anxiety, physical inactivity, and social isolation may also develop, which contribute further to the social stigma and burden caused by psoriasis [3-5]. Psoriasis is also strongly associated with diabetes and major cardiovascular events, with excess mortality seen in patients with psoriasis affecting $10 \%$ or more of the body surface area [6-9]. An important aspect of managing psoriatic disease is to address the psychosocial and physical symptoms through support, in which patients often benefit from sharing their experiences with a community of psoriatic patients $[3,5]$.

Traditionally, patients have not been included in contributing to research design and analysis because of under-recognition of the value of their contributions as research partners $[10,11]$. There is a broader challenge of engaging patients in research that includes the lack of patient expertise or involvement. If only the perspective of researchers is represented, topics of less importance to patients may be explored, thus providing results that are of limited use. Given increasing social media utilization and the proportion of adults that seek health information from the internet, online crowdsourcing platforms have become innovative tools that actively engage patients in the research process [12-14]. Crowdsourcing solicits creative ideas from paid consumers who complete a requested task. Although crowdsourcing in its most general sense involves non-selective participation, a major advantage of diseasespecific portals is their potential for optimization of patient groups that have different needs than the general population [15-18].

There are several online portals that invite patients to participate in the research process by contributing health data or ideas and observing the participants' results (Table 1). PatientsLikeMe allows patients to share information about their disease with other participants and companies to develop improved healthcare tools or services, in which 5789 psoriasis patients are registered $[19,20]$. However, data is outsourced to partner pharmaceutical and clinical trials research companies, which some patients may not feel comfortable with [21]. The Global Parents for Eczema Research analyzed "patient and caregiver chatter" from social networks for atopic dermatitis (AD), identifying topics on topical treatments, the side effects of steroids, and diet [22]. CureTogether, a website with patient-generated symptom and treatment data on skin diseases, was created in order to diversify participants and increase participation and has 335 enrolled psoriasis patients [23, 24].

Similarly, Citizen Pscientist (CP) was developed as a method of support and education for the psoriatic disease community. However, CP is distinct from any other crowdsourced projects in that patients are directly involved in their own research as both data contributors and research analysts. The CP research project was created in 2015 by the National Psoriasis Foundation (NPF) and funded through a Pipeline-to-Proposal Award from a US non-profit organization, the PCORI [25]. The objective of $\mathrm{CP}$ is to engage psoriasis patients in the research process, as the role of both subjects and "pscientists." The initiation and implementation of $\mathrm{CP}$ were overseen by a CP governing council of patients, psoriatic disease researchers, and NPF staff. Here, we describe a novel approach of patient-driven research and share the experience of implementing a psoriatic disease-specific interactive patient database through CP. 


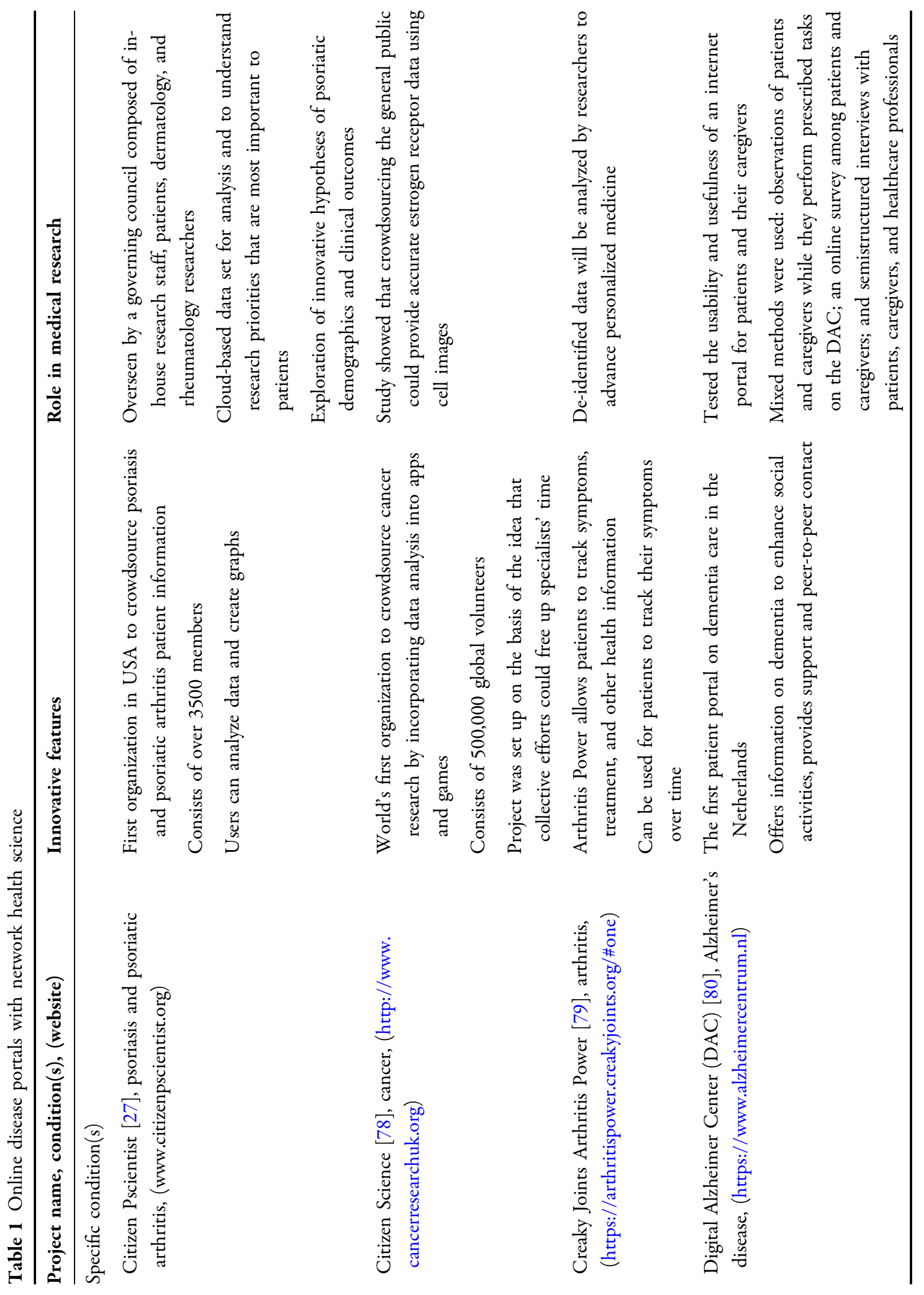




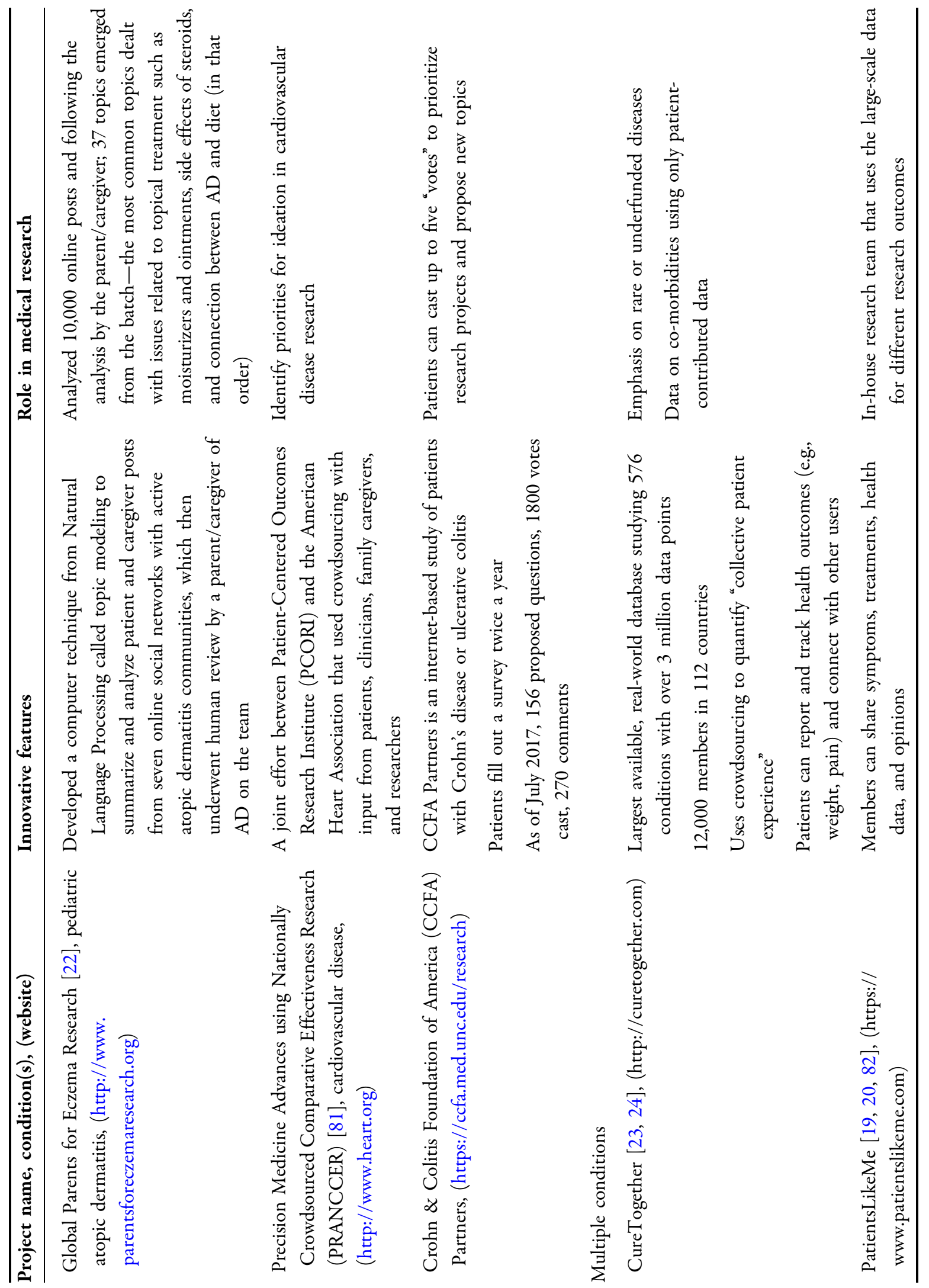




\section{METHODS}

\section{CP Structure and Survey}

A CP governing council, composed of patients, researchers, and NPF staff generated 59 initial survey questions asking about health data on demographics, family history, symptoms, disease onset, psoriasis subtypes, disease severity, triggers, quality of life, associated co-morbidities, and response to interventions. The $\mathrm{CP}$ survey followed the Checklist for Reporting Results of Internet E-Surveys (CHERRIES) reporting criteria [26].

\section{Patient Recruitment and Enrollment}

Patients were invited to enroll in CP through a website (www.citizenpscientist.org) promoted by NPF. Individuals registered on the CP portal with a valid e-mail address, which allowed for the establishment of a single user profile. Electronic informed consent was obtained from all participants at enrollment.

Recruitment was conducted through NPF's patient membership listserve, main website, social media outlets, the Patient Navigation Center, Psoriasis Advance magazine, and promotional materials used at NPF in-person events. The NPF currently has a strong social media presence for adequate marketing potential, as demonstrated by 71,190 "likes" and 68,054 followers on Facebook, 19,700 followers on Twitter, and 2180 followers on Linked-In.

\section{Patient-Generated Data}

CP's most unique aspect allows patients to explore de-identified patient-generated data and examine the relationship between any two variables from the intake survey. Such findings are posted as charts on the website, which are named "discovery charts." After the results are posted online, any of the users can comment on the output. The features of openly publishing results to the $\mathrm{CP}$ community promote further explorations or allow patients to discuss or relate the findings to their own experiences or knowledge about their condition. Researchers, 


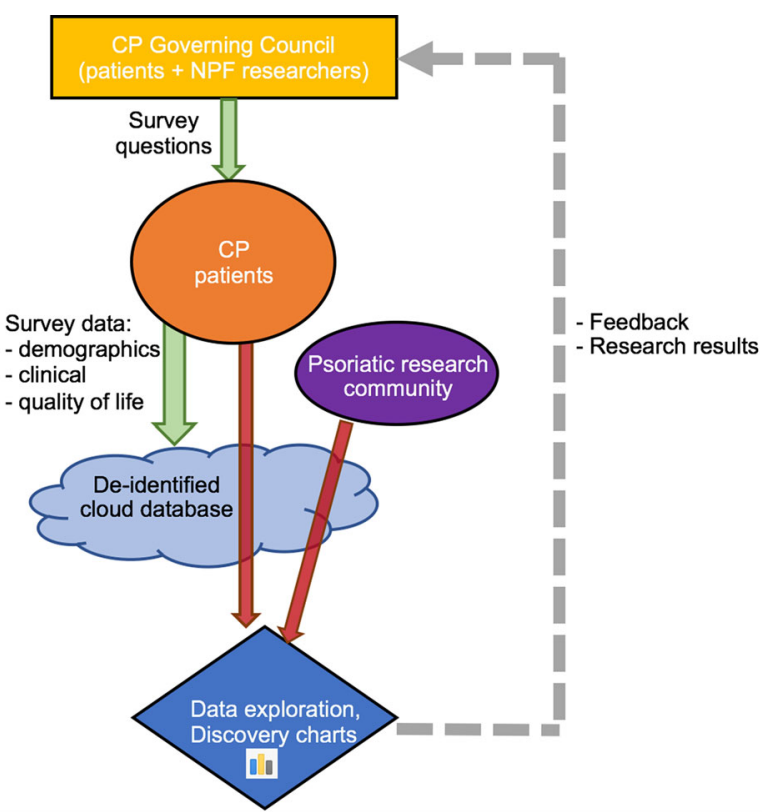

Fig. 1 Workflow process of Citizen Pscientist. The CP Governing Council helps develop survey questions, which the CP patients answer. This data is then stored in a deidentified cloud database. Then, CP patients and the psoriatic research community can analyze the data, post discoveries, and generate discussion about the findings. These activities inform future survey questions and CP initiatives

such as those at academic universities, are also able to analyze the data (Fig. 1).

The content of new survey questions can be informed by patient input. The $\mathrm{CP}$ governing council previously published on patient priorities for comparative effectiveness research (CER) within the $\mathrm{CP}$ community and our survey reflects these topics of importance identified by patients [27].

\section{Data Analysis}

Patient demographics and clinical characteristics were tabulated by frequency using Microsoft Excel and STATA Special Edition, version 14.2 (College Station, TX). Geographical data was analyzed using ArcGIS Online mapping software (Environmental Systems Research Institute, Redlands, CA, USA). All patient-generated discovery charts up to September 2017 were analyzed for the content of topics. Missing data were included in the analysis and were specified as "no response" in the results table.

\section{Compliance with Ethics Guidelines}

Institutional review board (IRB) approval for CP was obtained from Genetic Alliance, which includes patients outside of the USA.

\section{RESULTS}

\section{Patient Participation}

As of May 2017, there were 3534 users on the CP platform contributing over 200,000 data points. CP members were well distributed geographically in the USA; there were members from every state and territory (Fig. 2). Globally, CP members were primarily from the USA, UK, France, India, and Australia (Fig. 3). CP members were also observed from Fiji, Samoa, New Zealand, Iceland, Saudi Arabia, Singapore, Taipei, Finland, Syria, Greece, Austria, Russia, the Caribbean, and South Africa, among others.

The activity of CP users over time is monitored. Unique visits to the site averaged 800 per month from May to December 2017 for a total of 6409 visits by CP users, and the highest activity was in July and August.

\section{Patient Demographics}

At baseline, 3246 (91.9\%) reported having physician-diagnosed psoriasis and 1545 (43.7\%) reported having physician-diagnosed psoriatic arthritis (Table 2). A small percentage of CP users $(8.1 \%)$ did not specify psoriasis status. The majority of CP users are greater than 40 years of age; few users of the CP platform are below the age of $18(1.6 \%)$. There is a female predominance $(60.9 \%)$ among the CP community with male members only representing approximately $27.3 \%$, though $11.8 \%$ did not answer data on sex. The racial background of the CP community was determined from questions on parental ancestry rather than self-report of ethnicity. The CP membership is predominantly White/Caucasian (69.6\%), followed by Asian (4.9\%), 


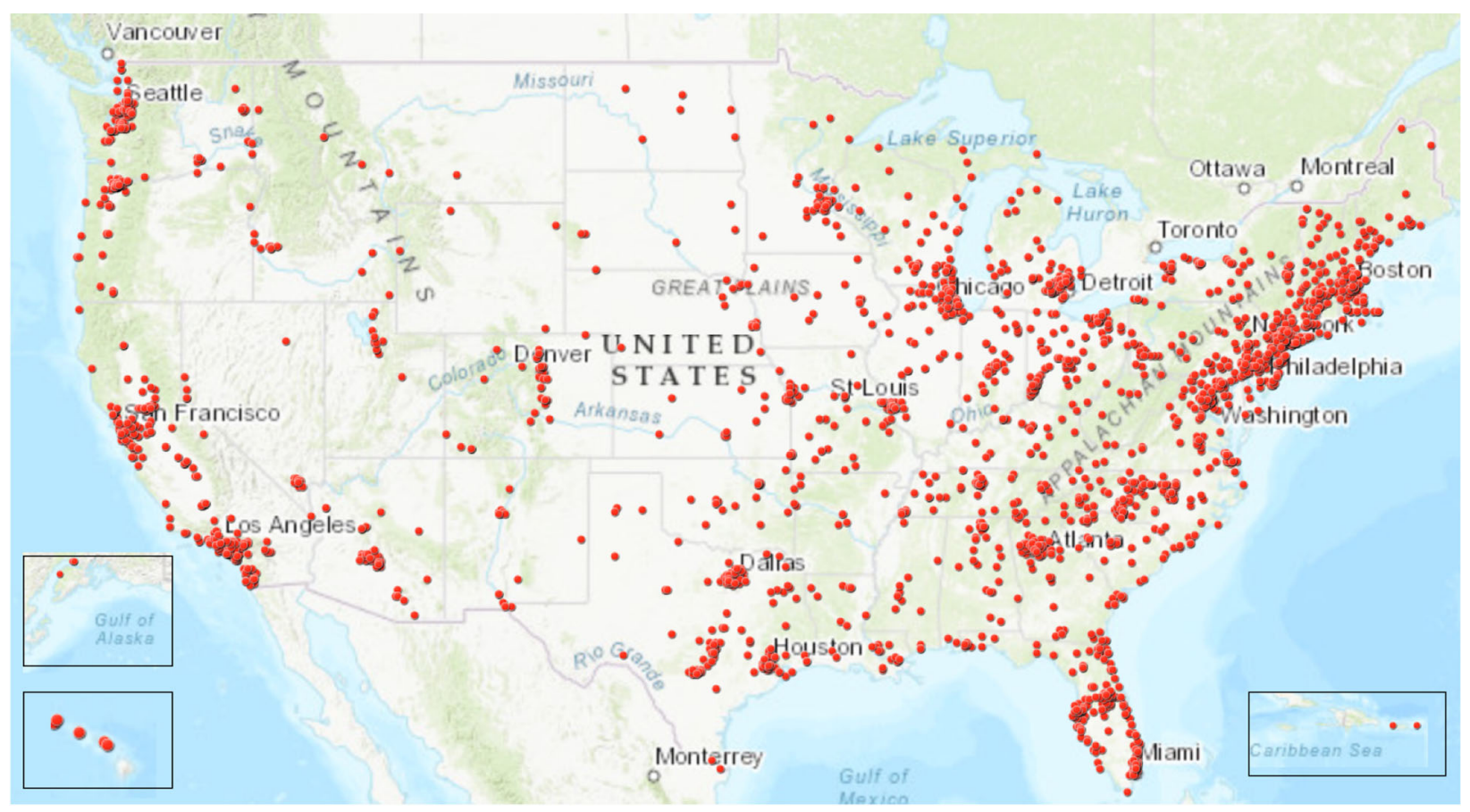

Fig. 2 Geographical distribution of CP users in the USA, October 2017

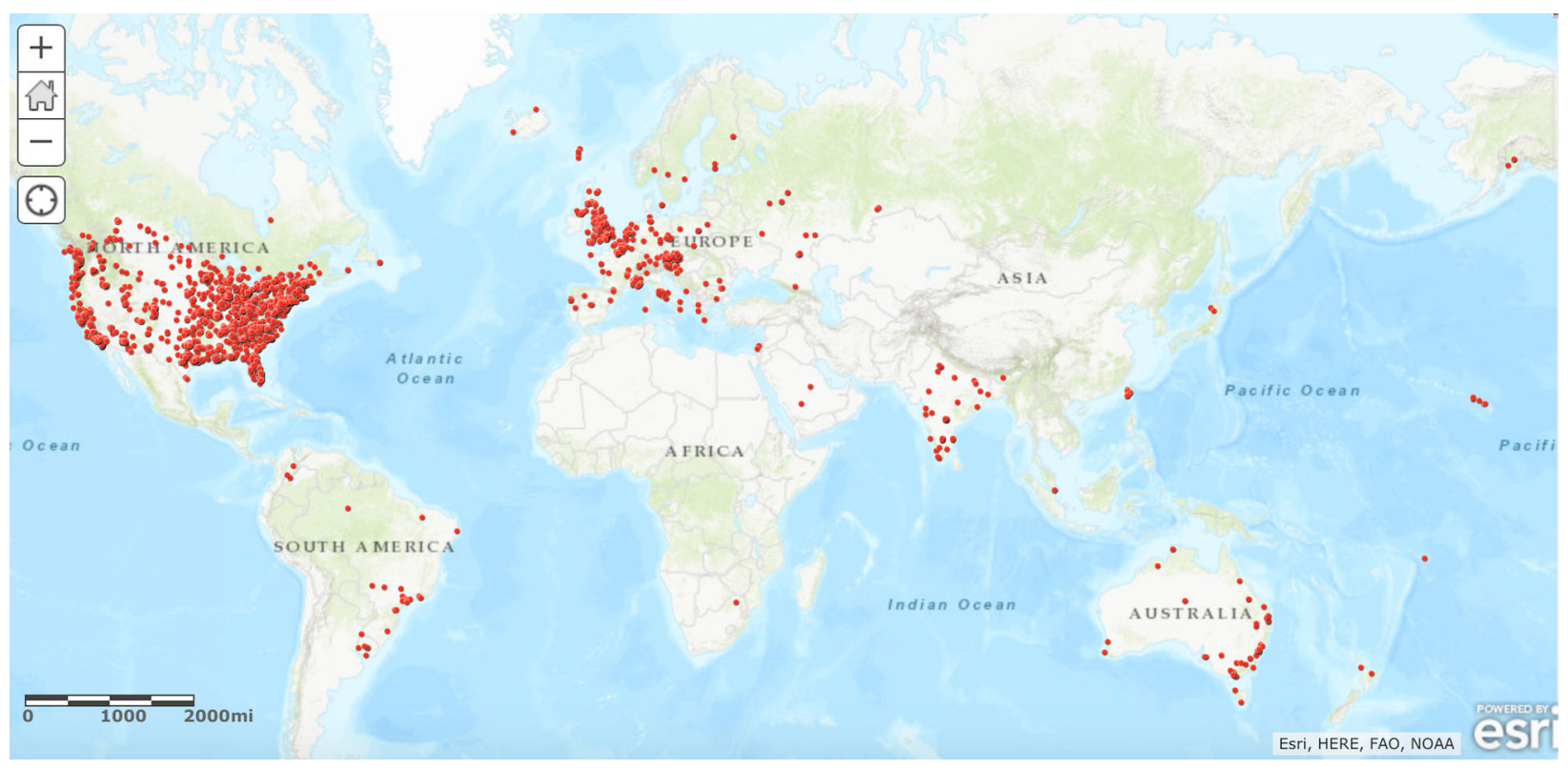

Fig. 3 Worldwide geographical distribution of CP users, October 2017, $n=3404$

Hispanic/Latino (4.5\%), American Indian/Alaskan Native (3.4\%), Black/African American (1.7\%), and Native Hawaiian/Pacific Islander (0.3\%).
Approximately $38 \%$ of CP users do not consume alcohol, while a similar proportion report having six drinks or less in 1 week and a minority consumes more than seven drinks per 
Table 2 Demographics of CP members, May 2017

\begin{tabular}{|c|c|}
\hline Member characteristic & $\begin{array}{l}\text { Frequency, } \\
n(\%)\end{array}$ \\
\hline \multicolumn{2}{|l|}{ Disease } \\
\hline Psoriasis $^{\mathrm{a}}$ & 3246 (91.9) \\
\hline Psoriasis with psoriatic arthritis & $1545(43.7)$ \\
\hline No response $\mathrm{e}^{\mathrm{a}}$ & $288(8.1)$ \\
\hline \multicolumn{2}{|l|}{$\operatorname{Age}^{\mathrm{a}}$} \\
\hline Under 18 & $56(1.6)$ \\
\hline $18-30$ & $383(10.8)$ \\
\hline $31-40$ & $541(15.3)$ \\
\hline $41-50$ & $699(19.8)$ \\
\hline $51-65$ & $1105(31.3)$ \\
\hline Over 65 & $354(10.0)$ \\
\hline No response & $396(11.2)$ \\
\hline \multicolumn{2}{|l|}{ Gender $^{\mathrm{b}}$} \\
\hline Female & $2151(60.9)$ \\
\hline Male & $964(27.3)$ \\
\hline No response & $419(11.8)$ \\
\hline \multicolumn{2}{|l|}{ Racial/ethnic background ${ }^{*, b}$} \\
\hline White/Caucasian & $4918(69.6)$ \\
\hline Asian & $346(4.9)$ \\
\hline Hispanic/Latino & $317(4.5)$ \\
\hline American Indian/Alaskan Native & $242(3.4)$ \\
\hline Black/African American & $122(1.7)$ \\
\hline Native Hawaiian/Pacific Islander & $19(0.3)$ \\
\hline Other & $1253(17.7)$ \\
\hline No response & $979(13.9)$ \\
\hline \multicolumn{2}{|c|}{ Alcohol consumption (drinks per week) } \\
\hline $1-3$ & $972(27.5)$ \\
\hline $4-6$ & $295(8.3)$ \\
\hline $7-9$ & $191(5.4)$ \\
\hline 10 or more & $191(5.4)$ \\
\hline I don't drink & $1338(37.9)$ \\
\hline No response & $547(15.4)$ \\
\hline
\end{tabular}

Table 2 continued

\begin{tabular}{lc}
\hline Member characteristic & $\begin{array}{c}\text { Frequency, } \\
n(\%)\end{array}$ \\
\hline Smoking (cigarettes per day) & $208(5.9)$ \\
$1-10$ & $167(4.7)$ \\
$11-20$ & $57(1.6)$ \\
$>20$ & $179(5.1)$ \\
Not daily smoker & $2365(67.0)$ \\
Non-smoker & $558(15.8)$ \\
No response & $1296(36.7)$ \\
Immediate family with psoriasis ${ }^{\mathrm{a}}$ & $921(26.1)$ \\
Immediate family with psoriatic & \\
arthritis & \\
\hline *Total sum $>100 \%$ because of multiple responses by \\
subjects \\
a Calculated using total number of subjects $(n=3534)$ \\
b Calculated using ethnic data from both mother and \\
father $(n=7068)$
\end{tabular}

week (11\%). The majority of CP users $(67 \%)$ do not smoke, with $12.2 \%$ smoking one or more cigarettes per day. Regarding family history, $36.7 \%$ of the CP users report an immediate family member with psoriasis and $26.1 \%$ report an immediate family member with psoriatic arthritis.

\section{Clinical Characteristics}

It is well known from the literature that psoriatic disease patients have an increased risk of cardiovascular and autoimmune diseases [7, 28-32]. The most frequently reported comorbidities among the CP users include high blood pressure (22.4\%), high cholesterol $(20.1 \%)$, high triglycerides $(9.6 \%)$, sleep apnea (10.1\%), thyroid disease (11.2\%), and eczema/ atopic dermatitis (12.2\%) (Table 3). Approximately $20 \%$ of CP users report having an autoimmune-related comorbidity. One-fifth of CP users did not report any of the listed comorbid conditions.

Psoriasis may be divided into several clinical subtypes. The majority of $\mathrm{CP}$ users reported 
Table 3 Clinical characteristics of $\mathrm{CP}$ members, May 2017

\begin{tabular}{|c|c|}
\hline Member characteristic & Frequency, $n(\%)$ \\
\hline \multicolumn{2}{|l|}{ Comorbidities,a } \\
\hline High blood pressure & $790(22.4)$ \\
\hline High cholesterol & $709(20.1)$ \\
\hline Thyroid disease & $396(11.2)$ \\
\hline Sleep apnea & $357(10.1)$ \\
\hline High triglycerides & $341(9.6)$ \\
\hline Eczema/atopic dermatitis & $431(12.2)$ \\
\hline Type 2 diabetes mellitus & $193(5.5)$ \\
\hline Fatty liver disease & $159(4.5)$ \\
\hline Cancer & $144(4.1)$ \\
\hline Rheumatoid arthritis & $136(3.8)$ \\
\hline Coronary artery disease & $87(2.5)$ \\
\hline Uveitis & $74(2.1)$ \\
\hline Sjögren's syndrome & $60(1.7)$ \\
\hline Liver disease & $48(1.4)$ \\
\hline Celiac disease & $49(1.4)$ \\
\hline Crohn disease & $44(1.2)$ \\
\hline Stroke & $43(1.2)$ \\
\hline Alopecia areata & $31(0.9)$ \\
\hline Lupus & $27(0.8)$ \\
\hline Type 1 diabetes mellitus & $21(0.6)$ \\
\hline Multiple sclerosis & $15(0.4)$ \\
\hline Cutaneous T cell lymphoma & $4(0.1)$ \\
\hline Parkinson's disease & $5(0.1)$ \\
\hline Other & $220(6.2)$ \\
\hline None & $675(19.1)$ \\
\hline No response & $349(9.9)$ \\
\hline \multicolumn{2}{|l|}{ Psoriasis subtype ${ }^{*, a}$} \\
\hline Plaque & $2459(69.6)$ \\
\hline Guttate & $573(16.2)$ \\
\hline Inverse & $485(13.7)$ \\
\hline Pustular & $350(9.9)$ \\
\hline
\end{tabular}

Table 3 continued

\begin{tabular}{|c|c|}
\hline Member characteristic & Frequency, $n(\%)$ \\
\hline Erythrodermic & $116(3.3)$ \\
\hline Not sure & $1(<0.1)$ \\
\hline No response & $294(8.3)$ \\
\hline \multicolumn{2}{|l|}{ Psoriasis location ${ }^{*, a}$} \\
\hline Scalp & $2100(59.4)$ \\
\hline Arm/legs & $1948(55.1)$ \\
\hline Elbow/knees & $1799(50.9)$ \\
\hline Ears & $1521(43.0)$ \\
\hline Abdomen & $1429(40.4)$ \\
\hline Nails & $1173(33.2)$ \\
\hline Skin folds & $1013(28.7)$ \\
\hline Face & $932(26.4)$ \\
\hline Genitals & $854(24.2)$ \\
\hline Palms of hands & $584(16.5)$ \\
\hline Soles of feet & $561(15.9)$ \\
\hline No response & $227(6.4)$ \\
\hline \multicolumn{2}{|l|}{ Psoriasis severity ${ }^{a}$} \\
\hline Mild: $<5 \%$ BSA & $1303(36.9)$ \\
\hline Moderate: $5-10 \%$ BSA & $1035(29.3)$ \\
\hline Severe: $>10 \%$ BSA & $540(15.3)$ \\
\hline No response & $249(18.6)$ \\
\hline \multicolumn{2}{|c|}{ Affected joints in psoriatic arthritis ${ }^{b}$} \\
\hline Knuckles & $823(53.3)$ \\
\hline Knees & $815(52.7)$ \\
\hline Toes & 709 (45.9) \\
\hline Wrists & $664(43.0)$ \\
\hline Spine & $629(40.7)$ \\
\hline Ankles & $618(40.0)$ \\
\hline Shoulders & $581(37.6)$ \\
\hline Hips & $559(36.2)$ \\
\hline Neck & $546(35.3)$ \\
\hline Elbows & $485(31.4)$ \\
\hline
\end{tabular}


Table 3 continued

\begin{tabular}{ll}
\hline Member characteristic & Frequency, $\boldsymbol{n}$ (\%) \\
\hline Jaw & $241(15.6)$ \\
No response & $5(0.4)$ \\
\hline
\end{tabular}

$B S A$ body surface area

*Total sum $>100 \%$ due to multiple responses by subjects

${ }^{a}$ Calculated using total number of subjects $(n=3534)$

b Calculated using total number of subjects having psoriatic arthritis $(n=1545)$

having plaque psoriasis (69.6\%), followed by guttate $(16.2 \%)$, inverse $(13.7 \%)$, pustular (9.9\%), and erythrodermic (3.3\%) variants. The scalp, elbows/knees, and arms/legs were the most frequently reported areas with psoriatic involvement $(59.4 \%)$, followed by the ears and abdomen (43\% and 40\%, respectively). Psoriasis located on the face, genitals, and skin folds was in each case reported in about $25 \%$ of patients while the palms and soles of the hands and feet were reported among $17 \%$ of users. Approximately $33 \%$ of CP users report having nail psoriasis. In terms of psoriasis severity, $36.9 \%$ of the CP community reported less than $5 \%$ body surface area (BSA) involvement, 29.3\% reported $5-10 \%$ BSA, and $15.3 \%$ reported greater than $10 \%$ BSA. Psoriatic arthritis most frequently affected the knees and knuckles (53\%) followed by the toes, wrists, ankles, and spine (45\%).

\section{Participant-Generated Analysis}

A unique aspect of $\mathrm{CP}$ is that users can analyze their own data instantly online and share their findings with other users to generate discussions. As of June 2017, patients had posted 70 discovery charts generating 209 comments by the CP community. To examine the content of these patient-generated charts, a consecutive subset of 31 charts were further analyzed. Discovery charts were focused on demographics or clinical features of psoriatic disease (35\%), environmental triggers (32\%), and quality of life $(32 \%)$. The relationship of demographic characteristics was often displayed according to psoriasis severity, such as how smoking varies among those with different psoriasis severity.
The discovery charts posted on clinical features examined, for example, which areas of the body were affected by psoriasis and which areas were the most bothersome stratified by psoriatic arthritis status (Fig. 4), and which areas correlated with sleep disturbance. In addition, the frequency of comorbidities was explored among different patient subsets. The subtype of psoriasis was compared to several variables, such as current treatments.

The discovery charts that examined environmental triggers focused on the seasonal association of flares or flare triggers such as stress, skin injury, or smoking. Alternatively, exploration of exercise and meditation were identified to reduce flares. The association between stress reduction and psoriasis severity was examined.

Quality of life was explored through several discovery charts examining activities that are prevented by psoriatic arthritis. The association between self-consciousness and gender was examined, as well as discussions of overall life satisfaction.

\section{DISCUSSION}

$\mathrm{CP}$ is a powerful tool that empowers the psoriatic disease community by allowing patients to take ownership in learning more about their disease and to contribute back through self-directed research. Though there have been several other disease portals that rely on crowdsourcing and online forums, CP is the only one that promotes direct analysis of data by the users and openly displays this information for rapid patient-directed education and support.

Since CP attracts motivated patients who enroll and provide data through an online interface, it is expected that certain groups may be over-represented. Indeed, we observed a relatively high proportion of patients with psoriatic arthritis (43.7\%), which is toward the upper limit of an estimated range of $7-48 \%$ seen in epidemiologic studies and is higher than population-based estimates of approximately $10 \%$ [33-37]. This indicates that individuals suffering from psoriatic arthritis may be more motivated to enroll in $\mathrm{CP}$ or that patients with more severe 
Most bothersome body surface by type of psoriatic disease.

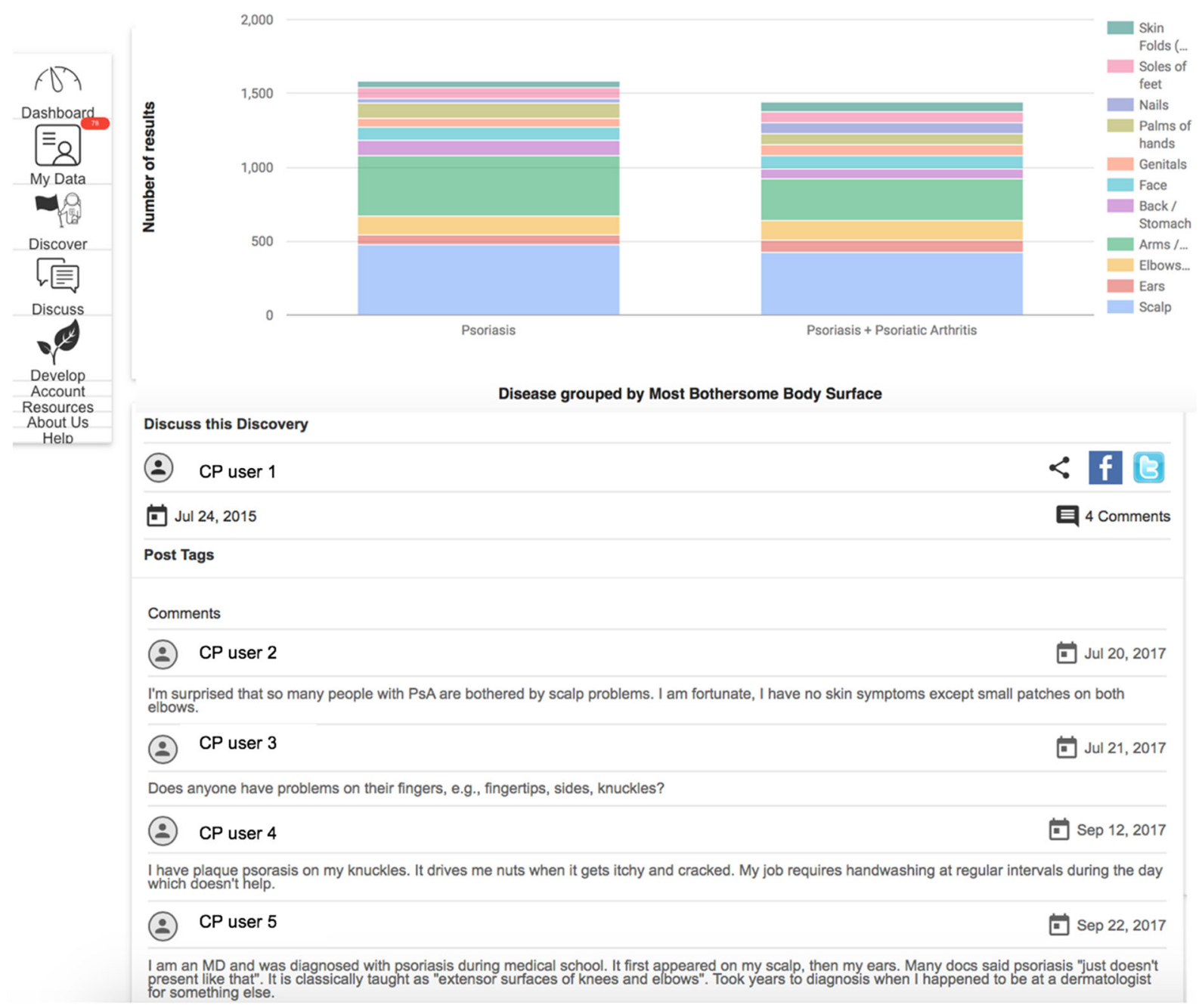

Fig. 4 Patient-generated analysis of most bothersome psoriasis sites. Screenshot from the CP online patient portal. Note the diverse discussion and feedback from personal experiences

disease (in which the prevalence of PsA is increased) are more motivated to enroll. Similarly, we observed a higher proportion of female patients, whereas large-scale epidemiological studies have found no clear gender predilection for psoriasis $[2,38]$. Our results are consistent with the observation that women more often than men engage in health information-seeking behaviors [39].

The ages of CP participants follow a skewed distribution favoring ages above 41. Interestingly, the majority of participants are between 51 and 65 years $(31.3 \%)$. The current CP community has a relatively low number of minorities, possibly reflecting our advertising that was limited to NPF members. Though questions about socioeconomic status were not asked in the CP survey, the NPF membership from which the $\mathrm{CP}$ individuals were drawn from are typically of a higher educational and income status than the general population. Approximately $17 \%$ of $\mathrm{CP}$ users reported current smoking behaviors, which is slightly greater than smokers found from US population studies. According to the Centers for Disease Control and Prevention, $13.6 \%$ of women in the USA smoked compared to $16.7 \%$ of men in 2015 [40]. A study analyzing data from the 
Nurses' Health Study, the Nurses' Health Study II, and the Health Professionals' Follow-up Study found that current or former smokers were more likely to develop psoriasis than nonsmokers and with increased smoking duration the risk for psoriasis increased [41]. Approximately $47 \%$ of the CP members report alcohol consumption, with the majority consuming 1-3 drinks per week (27.5\%) and only a minority reporting greater than 10 drinks per week (5.4\%). Alcohol abuse has been associated with a greater risk for developing or worsening psoriasis [42]. Overall, the low prevalence of alcohol use among the CP community may be due to the female predominance, as women are less likely to be alcohol misusers [43], and that patients who participate in the CP initiative may be also less likely to engage in alcohol consumption. Within the CP community, 37\% of members reported at least one immediate family member with psoriasis. This is consistent with studies showing that approximately $40 \%$ of patients with psoriasis or psoriatic arthritis have a family history of these disorders in firstdegree relatives [44].

The high rate of disorders of impaired metabolism among the CP community is consistent with previous studies demonstrating a greater likelihood of obesity, hypertension, hypertriglyceridemia, hypercholesterolemia, diabetes, and sleep apnea [45-51]. In addition, $20 \%$ of CP users reported an autoimmune-related comorbidity consistent with prior studies detecting an increased autoimmune disease prevalence among patients with psoriasis and PsA such as uveitis, alopecia areata, celiac disease, systemic sclerosis, and Crohn disease $[32,52,53]$.

The type, severity, and location of psoriasis reported among the $\mathrm{CP}$ users are parallel to findings in the literature, with the exception of pustular psoriasis occurring twice higher than expected. Chronic plaque psoriasis is the most common variant of psoriasis with the literature reporting $55-79 \%$ of patients with psoriasis identified as the plaque type $[54,55]$. The majority of $\mathrm{CP}$ patients with psoriasis have moderate to severe disease, while populationbased estimates have suggested that about 20\% have moderate to severe psoriatic disease [56].
The most common areas include the scalp, elbows or knees, and gluteal cleft. Psoriatic arthritis has several different patterns of joint involvement [57], and we also found a wide distribution of joint involvement among $\mathrm{CP}$ users with psoriatic arthritis, the most common areas being the knuckles, knees, toes, wrists, spine, and ankles.

The patient-centered discoveries of $\mathrm{CP}$ add value to psoriasis knowledge by showing what patients consider important about their disease. The current literature is sparse for these highpriority topics identified by psoriasis patients. There are six studies that discuss environmental triggers of psoriasis [58-63], while 10 articles explore the seasonality of psoriasis [64-73]. These articles do not provide clear answers, may be resource-intensive to develop, and might have limited quality in the setting of confounding variables. Thus, there is an opportunity for the CP platform to fill these gaps of highly prioritized topics for psoriasis patients.

CP may redirect researchers to focus on studying disease factors that are the most important to patients. Furthermore, CP's influence on research has the potential for enabling researchers and physicians to connect with ongoing questions generated by patients. For example, a survey that ranked the patient's top priority CER topics showed that the following were the highest importance to $\mathrm{CP}$ patients: comparing the effectiveness, safety, risk, and costs of treatment; diet or remedies; and communication or management strategies. Specifically, the most popular CER questions were comparing biologics to methotrexate, treat-totarget management for psoriasis, comparisons of home versus office-based phototherapy, and differences between scalp psoriasis treatment formulations [27]. Although patient-physician communication is important in determining patient needs, direct feedback from CP is valuable information for guiding future research efforts and patient care [74].

Another unique aspect of $\mathrm{CP}$ is that messages can be posted by participants in response to the displayed discovery charts, which may result in further discussion and analysis. For example, a data-driven discussion debated whether the observed results had statistical significance. As a 
result of the high interest in the debated topic, researchers may consider following up on the discussion points raised by the users.

The initial efforts of CP were focused in the USA, as recruitment was implemented through the NPF. However, we were surprised by the reach of the CP platform to countries outside of the USA. As the number of international participants continues to increase, we will translate the survey to other languages. The fact that the intake survey and CP website are in English and from a US-based website may also contribute to the limited diversity of the subjects in our summarized results.

Additionally, the activity of CP by users has remained high over time, with the most active months during the Summer. The average of 800 visits per month and total unique visits of 6409 in 2017 suggest that users may be visiting the site multiple times, as the visits exceed the total count of registered CP users.

Psoriasis patients have expressed that $\mathrm{CP}$ adds significant value to their view of research, their general psoriasis knowledge, and their well-being. One member stated that $\mathrm{CP}$ is valuable because it gives patients the ability to be part of the effort to find a cure. Even though discussion groups and online forums are valuable in letting patients share their experiences with others, $\mathrm{CP}$ is unique in that patients can influence the direction of future research. It lets researchers know what questions matter the most to patients in a direct and quantifiable way. In addition, patients stated that $\mathrm{CP}$ is valuable because it lets them know what other patients' concerns are by means of quantifiable information in the form of easy-toread and easy-to-understand charts and graphs. They get an instant picture of other patients' concerns and trends in the entire community's response to survey questions. Another CP member shared the fact that awareness of overlapping disease features between patients refines patients' understanding of psoriasis further. Importantly, CP emphasizes to those living with psoriasis that they are not alone. Individuals can anonymously share their toughest moments experiencing psoriasis, which can be translated into impactful science.

\section{Limitations}

With this interactive data tool, however, there is a risk of misinterpretation of the results by the CP users. For example, a comment was posted to a discovery chart stating that fizzy drinks and sugar could help psoriasis, which was the opposite interpretation of what the results displayed. Future enhancements to the platform could consider a dermatologist or research moderator to help users understand the results correctly. It is also possible that an analysis led by patients could induce potential conflicts of interests and biases that could favor inaccurate but desired health outcomes. Therefore, the CP discovery graphs must be interpreted with caution.

Self-reported data may not provide accurate information, especially when examining clinical factors in comparison to deriving health information from electronic health records. However, more insight into patient priorities and a wider variety of patients are reached when mining $\mathrm{CP}$ crowdsourced data. A correlation between self-administered scoring of disease severity to physician-generated clinical measures of psoriasis severity using the Psoriasis Area Severity Index (PASI) has been reported, although a review of patient-reported outcomes determined that most do not assess validity [75-77]. In our study, $91.9 \%$ of CP enrollees reported a physician-made diagnosis of psoriasis, but it is unclear if the remainder received a diagnosis of psoriasis from a different kind of provider or self-diagnosed their condition.

To improve the reliability of $\mathrm{CP}$ patientgenerated data, a validation of the self-reported diagnoses through a review of patient medical records will be performed by $\mathrm{CP}$ researchers. After $10 \%$ of our total CP patients are sampled and consented, their physicians will be asked to provide documentation of medical records that support or refute a patient's psoriasis diagnosis. As more robust data is generated by $\mathrm{CP}$, the NPF researchers will conduct a more formal analysis of summary data. 


\section{CONCLUSIONS}

$\mathrm{CP}$ is a unique research platform that encourages meaningful data exchange for psoriatic disease research. Other patient portals have used crowdsourced research for science innovation; however, none, to our knowledge, have integrated patients into the research development or analysis process. Patient-generated analyses in CP have demonstrated interest in demographics and clinical features of psoriasis, followed by environmental triggers and seasonality, indicating that the patient perspective can help guide future research areas.

Future efforts to enhance CP will focus on several areas. One priority is recruitment of a more racially diverse population through comprehensive outreach methods. Another priority is maintaining the engagement of users, through new survey questions and by expanding the interface to a mobile application. A subset of the CP data is currently being validated with medical records to assess the accuracy and quality of the self-reported information. Finally, the addition of real-time activity, fitness tracking, and DNA or other biospecimens may also be explored. In these ways, CP can continue to contribute to patientcentered research that improves the quality of life of psoriatic patients globally.

\section{ACKNOWLEDGMENTS}

We are grateful to the many patients who have contributed to the CP initiative. We are thankful for the CP patients who participated in study design and implementation. These patients continue to contribute valuable feedback and improvements to $\mathrm{CP}$ as active members of our $\mathrm{CP}$ governing council.

Funding. The development of $\mathrm{CP}$ was funded by the National Psoriasis Foundation and by a Patient-Centered Outcomes Research Institute (PCORI) Pipeline-to-Proposal Award. No funding was received for publication of this article.
Authorship. All named authors meet the International Committee of Medical Journal Editors (ICMJE) criteria for authorship for this article, take responsibility for the integrity of the work as a whole, and have given their approval for this version to be published.

Disclosures. Isabelle M. Sanchez, Marilyn T. Wan, Ladan Afifi, Frank Doris, Alisha Bridges, Marc Boas, Brian Lafoy, and Sarah Truman have nothing to disclose. Wilson Liao is funded in part by grants from the National Institutes of Health (R01AR065174, U01AI119125) and has served as a research investigator for Abbvie, Janssen, Novartis, and Pfizer. Lindsey Shankle is employed by the National Psoriasis Foundation. The Foundation receives unrestricted financial support from AbbVie, Inc, Amgen, Inc, Celgene Corporation, Eli Lilly and Co, Janssen Biotech, Inc, LEO Pharma Inc, Mallinckrodt Pharmaceuticals, Novartis Pharmaceuticals, Pfizer, Inc, and Valeant Pharmaceuticals International, Inc. Michael P. Siegel is employed by the National Psoriasis Foundation. The Foundation receives unrestricted financial support from AbbVie, Inc, Amgen, Inc, Celgene Corporation, Eli Lilly and Co, Janssen Biotech, Inc, LEO Pharma Inc, Mallinckrodt Pharmaceuticals, Novartis Pharmaceuticals, Pfizer, Inc, and Valeant Pharmaceuticals International, Inc. April W. Armstrong has served as investigator, advisor, and/or consultant to AbbVie, Janssen, Novartis, Lilly, Regeneron, Sanofi, and Ortho Dermatologics. Joel M. Gelfand is funded by NIAMS K24AR064310 and has served as a consultant for BMS, Coherus (DSMB), Dermira, GSK, Janssen Biologics, Menlo Therapeutics, Novartis Corp, Regeneron, Dr. Reddy's labs, Sanofi, and Pfizer Inc., receiving honoraria; and receives research grants (to the Trustees of the University of Pennsylvania) from Abbvie, Janssen, Novartis Corp, Regeneron, Sanofi, Celgene, and Pfizer Inc.; and received payment for continuing medical education work related to psoriasis that was supported indirectly by Lilly, Valeant, and Abbvie. Joel M. Gelfand is also a co-patent holder of resiquimod for treatment of cutaneous $\mathrm{T}$ cell lymphoma. Junko Takeshita is supported by NIAMS K23-AR068433. Junko Takeshita also receives a research grant from 
Pfizer Inc (to the Trustees of the University of Pennsylvania) and has received payment for continuing medical education work related to psoriasis that was supported indirectly by Eli Lilly and Novartis. Ana-Maria Orbai is funded in part by grants from the National Institutes of Health (P30 AR070254-01), the Rheumatology Research Foundation (RRF Scientist Development Award), and the Staurulakis Discovery Award. Ana-Maria Orbai has served as an investigator and received research funding (to Johns Hopkins University) from Abbvie, Celgene, Janssen, Horizon, Eli Lilly, and Novartis. In addition, A.M.O. has also served as a consultant for Eli Lilly, Janssen, Novartis, Pfizer, and UCB. Jashin J. Wu is an investigator for AbbVie, Amgen, Eli Lilly, Janssen, Novartis, and Regeneron.

Compliance with Ethics Guidelines. IRB approval for CP was obtained from Genetic Alliance, which includes patients outside of the USA.

Data Availability. The data sets generated and/or analyzed during the current study are available from the NPF on reasonable request. Please contact the corresponding author for more information.

Open Access. This article is distributed under the terms of the Creative Commons Attribution-NonCommercial 4.0 International License (http://creativecommons.org/licenses/ by-nc/4.0/), which permits any noncommercial use, distribution, and reproduction in any medium, provided you give appropriate credit to the original author(s) and the source, provide a link to the Creative Commons license, and indicate if changes were made.

\section{REFERENCES}

1. Goff KL, Karimkhani C, Boyers LN, et al. The global burden of psoriatic skin disease. Br J Dermatol. 2015;172(6):1665-8. https://doi.org/10.1111/bjd. 13715.
2. Rachakonda TD, Schupp CW, Armstrong AW. Psoriasis prevalence among adults in the United States. J Am Acad Dermatol. 2014;70(3):512-6. https://doi. org/10.1016/j.jaad.2013.11.013.

3. Bewley A, Burrage DM, Ersser SJ, Hansen M, Ward C. Identifying individual psychosocial and adherence support needs in patients with psoriasis: a multinational two-stage qualitative and quantitative study. J Eur Acad Dermatol Venereol. 2014;28(6):763-70. https://doi.org/10.1111/jdv. 12174.

4. Takeshita J, Grewal S, Langan SM, et al. Psoriasis and comorbid diseases: epidemiology. J Am Acad Dermatol. 2017;76(3):377-90. https://doi.org/10. 1016/j.jaad.2016.07.064.

5. Balato N, Megna M, Palmisano F, et al. Psoriasis and sport: a new ally? J Eur Acad Dermatol Venereol. 2015;29(3):515-20. https://doi.org/10.1111/jdv. 12607.

6. Azfar RS, Seminara NM, Shin DB, Troxel AB, Margolis DJ, Gelfand JM. Increased risk of diabetes mellitus and likelihood of receiving diabetes mellitus treatment in patients with psoriasis. Arch Dermatol. 2012;148(9):995-1000. https://doi.org/10. 1001/archdermatol.2012.1401.

7. Gelfand JM, Neimann AL, Shin DB, Wang X, Margolis DJ, Troxel AB. Risk of myocardial infarction in patients with psoriasis. JAMA. 2006;296(14):1735-41. https://doi.org/10.1001/ jama.296.14.1735.

8. Noe MH, Shin DB, Wan MT, Gelfand JM. Objective measures of psoriasis severity predict mortality: a prospective population-based cohort study. J Invest Dermatol. 2017. https://doi.org/10.1016/j.jid.2017. 07.841.

9. Wan MT, Shin DB, Hubbard RA, Noe MH, Mehta NN, Gelfand JM. Psoriasis and the risk of diabetes: a prospective population-based cohort study. J Am Acad Dermatol. 2017. https://doi.org/10.1016/j. jaad.2017.10.050.

10. Ranard BL, Ha YP, Meisel ZF, et al. Crowdsourcingharnessing the masses to advance health and medicine, a systematic review. J Gen Intern Med. 2014;29(1):187-203. https://doi.org/10.1007/ s11606-013-2536-8.

11. Boote J, Telford R, Cooper C. Consumer involvement in health research: a review and research agenda. Health Policy. 2002;61(2):213-36.

12. Pew Research Center. Social media fact sheet. Pew Internet \& American Life Project. http://www. pewinternet.org/fact-sheet/social-media/\#. Accessed 31 Aug 2017. 
13. Fox S. Mobile, social health. Pew Internet \& American Life Project. http://www.pewinternet.org/ 2010/07/08/mobile-social-health/. Accessed 31 Aug 2017.

14. Balato N, Megna M, Di Costanzo L, Balato A, Ayala F. Educational and motivational support service: a pilot study for mobile-phone-based interventions in patients with psoriasis. $\mathrm{Br} \mathrm{J}$ Dermatol. 2013;168(1):201-5. https://doi.org/10.1111/j.13652133.2012.11205.x.

15. Armstrong AW, Cheeney S, Wu J, Harskamp CT, Schupp CW. Harnessing the power of crowds: crowdsourcing as a novel research method for evaluation of acne treatments. Am J Clin Dermatol. 2012;13(6):405-16. https://doi.org/10.2165/ 11634040-000000000-00000.

16. Armstrong AW, Harskamp CT, Cheeney S, Schupp CW. Crowdsourcing in eczema research: a novel method of data collection. J Drugs Dermatol. 2012;11(10):1153-5.

17. Armstrong AW, Harskamp CT, Cheeney S, Schupp $\mathrm{CW}$. Crowdsourcing for research data collection in rosacea. Dermatol Online J. 2012;18(3):15

18. Armstrong AW, Wu J, Harskamp CT, Cheeney S, Schupp CW. Crowdsourcing for data collection: a pilot study comparing patient-reported experiences and clinical trial data for the treatment of seborrheic dermatitis. Skin Res Technol. 2013;19(1):55-7. https://doi.org/10.1111/j.16000846.2012.00667.x.

19. PatientsLikeMe. https://www.patientslikeme.com/ about. Accessed 6 Oct 2017.

20. de la Loge C, Dimova S, Mueller K, et al. PatientsLikeMe ${ }^{\circledR}$ Online Epilepsy Community: patient characteristics and predictors of poor health-related quality of life. Epilepsy Behav E\&B. 2016;63:20-8. https://doi.org/10.1016/j.yebeh.2016.07.035.

21. Grajales FJ 3rd, Sheps S, Ho K, Novak-Lauscher H, Eysenbach G. Social media: a review and tutorial of applications in medicine and health care. J Med Internet Res. 2014;16(2):e13. https://doi.org/10. 2196/jmir.2912.

22. Capozza K, Shao Y, Zeng Q. "Crowdsourcing" a patient-centered research agenda for pediatric atopic dermatitis. Int J Dermatol. 2016;55(12):1414-6. https://doi.org/10.1111/ijd.13359.

23. Armstrong AW, Harskamp CT, Cheeney S, Wu J, Schupp CW. Power of crowdsourcing: novel methods of data collection in psoriasis and psoriatic arthritis. J Am Acad Dermatol. 2012;67(6):127381.e9. https://doi.org/10.1016/j.jaad.2012.05.013.
24. Carmichael A RD. Cure Together. http:// curetogether.com/. Accessed 6 Oct 2017.

25. Fleurence R, Selby JV, Odom-Walker K, et al. How the Patient-Centered Outcomes Research Institute is engaging patients and others in shaping its research agenda. Health Aff. 2013;32(2):393-400. https://doi.org/10.1377/hlthaff.2012.1176.

26. Eysenbach G. Improving the quality of Web surveys: the Checklist for Reporting Results of Internet E-Surveys (CHERRIES). J Med Internet Res. 2004;6(3):e34. https://doi.org/10.2196/jmir.6.3. e34.

27. Afifi L, Shankle L, Armstrong AW, et al. National Psoriasis Foundation priorities for patient-centered research: proceedings from the 2016 conference. J Psoriasis Psoriatic Arthritis. 2017;2(3):73-80.

28. Egeberg A, Skov L, Joshi AA, et al. The relationship between duration of psoriasis, vascular inflammation, and cardiovascular events. J Am Acad Dermatol. 2017;77(4):650-6.e3. https://doi.org/10. 1016/j.jaad.2017.06.028.

29. Kremers HM, McEvoy MT, Dann FJ, Gabriel SE. Heart disease in psoriasis. J Am Acad Dermatol. 2007;57(2):347-54. https://doi.org/10.1016/j.jaad. 2007.02.007.

30. Kim M, Choi KH, Hwang SW, Lee YB, Park HJ, Bae JM. Inflammatory bowel disease is associated with an increased risk of inflammatory skin diseases: a population-based cross-sectional study. J Am Acad Dermatol. 2017;76(1):40-8. https://doi.org/10. 1016/j.jaad.2016.08.022.

31. Bazso A, Szodoray P, Szappanos A, et al. Systemic autoimmune, rheumatic diseases and coinciding psoriasis: data from a large single-centre registry and review of the literature. Mediators Inflamm. 2015;2015:657907. https://doi.org/10.1155/2015/ 657907.

32. Wu JJ, Nguyen TU, Poon KY, Herrinton LJ. The association of psoriasis with autoimmune diseases. J Am Acad Dermatol. 2012;67(5):924-30. https:// doi.org/10.1016/j.jaad.2012.04.039.

33. Gelfand JM, Gladman DD, Mease PJ, et al. Epidemiology of psoriatic arthritis in the population of the United States. J Am Acad Dermatol. 2005;53(4):573. https://doi.org/10.1016/j.jaad. 2005.03.046.

34. Ibrahim G, Waxman R, Helliwell PS. The prevalence of psoriatic arthritis in people with psoriasis. Arthritis Rheum. 2009;61(10):1373-8. https://doi. org/10.1002/art.24608. 
35. Mease PJ, Gladman DD, Papp KA, et al. Prevalence of rheumatologist-diagnosed psoriatic arthritis in patients with psoriasis in European/North American dermatology clinics. J Am Acad Dermatol. 2013;69(5):729-35. https://doi.org/10.1016/j.jaad. 2013.07.023.

36. Radtke MA, Reich K, Blome C, Rustenbach S, Augustin M. Prevalence and clinical features of psoriatic arthritis and joint complaints in 2009 patients with psoriasis: results of a German national survey. J Eur Acad Dermatol Venereol. 2009;23(6):683-91. https://doi.org/10.1111/j.14683083.2009.03159.x.

37. Reich K, Kruger K, Mossner R, Augustin M. Epidemiology and clinical pattern of psoriatic arthritis in Germany: a prospective interdisciplinary epidemiological study of 1511 patients with plaquetype psoriasis. Br J Dermatol. 2009;160(5):1040-7. https://doi.org/10.1111/j.1365-2133.2008.09023.x.

38. Parisi R, Symmons DP, Griffiths CE, Ashcroft DM. Global epidemiology of psoriasis: a systematic review of incidence and prevalence. J Invest Dermatol. 2013;133(2):377-85. https://doi.org/10. 1038/jid.2012.339.

39. Renahy E, Parizot I, Chauvin P. Determinants of the frequency of online health information seeking: results of a Web-based survey conducted in France in 2007. Informatics Health Social Care. 2010;35(1):25-39. https://doi.org/10.3109/ 17538150903358784 .

40. Jamal AKB, Neff LJ, Whitmill J, Babb SD, Graffunder CM. Current cigarette smoking among adultsUnited States, 2005-2015. Morb Mortal Wkly Rep. 2016;605:1205-11.

41. Li W, Han J, Choi HK, Qureshi AA. Smoking and risk of incident psoriasis among women and men in the United States: a combined analysis. Am J Epidemiol. 2012;175(5):402-13. https://doi.org/10. 1093/aje/kwr325.

42. Murzaku EC, Bronsnick T, Rao BK. Diet in dermatology: part II. Melanoma, chronic urticaria, and psoriasis. J Am Acad Dermatol. 2014;71(6):1053, e1-e16. https://doi.org/10.1016/j.jaad.2014.06.016.

43. Hasin DS, Grant BF. The National Epidemiologic Survey on Alcohol and Related Conditions (NESARC) Waves 1 and 2: review and summary of findings. Soc Psychiatry Psychiatr Epidemiol. 2015;50(11):1609-40. https://doi.org/10.1007/ s00127-015-1088-0.

44. Gladman DD, Anhorn KA, Schachter RK, Mervart H. HLA antigens in psoriatic arthritis. J Rheumatol. 1986;13(3):586-92.
45. Langan SM, Seminara NM, Shin DB, et al. Prevalence of metabolic syndrome in patients with psoriasis: a population-based study in the United Kingdom. J Invest Dermatol. 2012;132(3 Pt 1):556-62. https://doi.org/10.1038/jid.2011.365.

46. Yeung H, Takeshita J, Mehta NN, et al. Psoriasis severity and the prevalence of major medical comorbidity: a population-based study. JAMA Dermatol. 2013;149(10):1173-9. https://doi.org/10. 1001/jamadermatol.2013.5015.

47. Armstrong AW, Harskamp CT, Armstrong EJ. Psoriasis and metabolic syndrome: a systematic review and meta-analysis of observational studies. J Am Acad Dermatol. 2013;68(4):654-62. https://doi.org/ 10.1016/j.jaad.2012.08.015.

48. Armstrong AW, Harskamp CT, Armstrong EJ. The association between psoriasis and hypertension: a systematic review and meta-analysis of observational studies. J Hypertens. 2013;31(3):433-42. https://doi.org/10.1097/hjh.0b013e32835bcce1 (discussion 42-3).

49. Armstrong AW, Harskamp CT, Armstrong EJ. Psoriasis and the risk of diabetes mellitus: a systematic review and meta-analysis. JAMA Dermatol. 2013;149(1):84-91. https://doi.org/10.1001/2013. jamadermatol.406.

50. Love TJ, Qureshi AA, Karlson EW, Gelfand JM, Choi HK. Prevalence of the metabolic syndrome in psoriasis: results from the National Health and Nutrition Examination Survey, 2003-2006. Arch Dermatol. 2011;147(4):419-24. https://doi.org/10. 1001/archdermatol.2010.370.

51. Qureshi AA, Choi HK, Setty AR, Curhan GC. Psoriasis and the risk of diabetes and hypertension: a prospective study of US female nurses. Arch Dermatol. 2009;145(4):379-82. https://doi.org/10. 1001/archdermatol.2009.48.

52. Charlton R, Green A, Shaddick G, et al. Risk of uveitis and inflammatory bowel disease in people with psoriatic arthritis: a population-based cohort study. Ann Rheum Dis. 2017. https://doi.org/10. 1136/annrheumdis-2017-212328.

53. Egeberg A, Khalid U, Gislason GH, Mallbris L, Skov L, Hansen PR. Association of psoriatic disease with uveitis: a Danish nationwide cohort study. JAMA Dermatol. 2015;151(11):1200-5. https://doi.org/10. 1001/jamadermatol.2015.1986.

54. Merola JF, Li T, Li WQ, Cho E, Qureshi AA. Prevalence of psoriasis phenotypes among men and women in the USA. Clin Exp Dermatol. 2016;41(5):486-9. https://doi.org/10.1111/ced. 12805. 
55. Tollefson MM, Crowson CS, McEvoy MT, Maradit Kremers $\mathrm{H}$. Incidence of psoriasis in children: a population-based study. J Am Acad Dermatol. 2010;62(6):979-87. https://doi.org/10.1016/j.jaad. 2009.07.029.

56. Yeung H, Takeshita J, Fau-Mehta NN, et al. Psoriasis severity and the prevalence of major medical comorbidity: a population-based study. JAMA Dermatol. 2013;149(10):1173-9.https://doi.org/10. 1001/jamadermatol.2013.5015

57. Garg A, Gladman D. Recognizing psoriatic arthritis in the dermatology clinic. J Am Acad Dermatol. 2010;63(5):733-48. https://doi.org/10.1016/j.jaad. 2010.02.061.

58. Castelino M, Eyre S, Upton M, Ho P, Barton A. The bacterial skin microbiome in psoriatic arthritis, an unexplored link in pathogenesis: challenges and opportunities offered by recent technological advances. Rheumatology (Oxford). 2014;53(5):777-84. https://doi.org/10.1093/ rheumatology/ket319.

59. Gunes AT, Fetil E, Akarsu S, Ozbagcivan O, Babayeva L. Possible triggering effect of influenza vaccination on psoriasis. J Immunol Res. 2015;2015:258430. https://doi.org/10.1155/2015/ 258430.

60. Pattison E, Harrison BJ, Griffiths CE, Silman AJ, Bruce IN. Environmental risk factors for the development of psoriatic arthritis: results from a casecontrol study. Ann Rheum Dis. 2008;67(5):672-6. https://doi.org/10.1136/ard.2007.073932.

61. Ruiz-Romeu E, Ferran M, Sagrista M, et al. Streptococcus pyogenes-induced cutaneous lymphocyte antigen-positive $\mathrm{T}$ cell-dependent epidermal cell activation triggers $\mathrm{TH} 17$ responses in patients with guttate psoriasis. J Allergy Clin Immunol. 2016;138(2):491-9.e6. https://doi.org/10.1016/j. jaci.2016.02.008.

62. Sbidian E, Eftekahri P, Viguier M, et al. National survey of psoriasis flares after 2009 monovalent H1N1/seasonal vaccines. Dermatology (Basel, Switzerland). 2014;229(2):130-5. https://doi.org/ $10.1159 / 000362808$.

63. Yan D, Afifi L, Jeon C, Cordoro KM, Liao W. A crosssectional study of psoriasis triggers among different ethno-racial groups. J Am Acad Dermatol. 2017;77(4):756-8.e1. https://doi.org/10.1016/j.jaad. 2017.04.1109.

64. Chua-Ty G, Goh CL, Koh SL. Pattern of skin diseases at the National Skin Centre (Singapore) from 1989-1990. Int J Dermatol. 1992;31(8):555-9.
65. Hancox JG, Sheridan SC, Feldman SR, Fleischer AB Jr. Seasonal variation of dermatologic disease in the USA: a study of office visits from 1990 to 1998. Int J Dermatol. 2004;43(1):6-11.

66. Harvell JD, Selig DJ. Seasonal variations in dermatologic and dermatopathologic diagnoses: a retrospective 15-year analysis of dermatopathologic data. Int J Dermatol. 2016;55(10):1115-8. https:// doi.org/10.1111/ijd.13229.

67. Kubota K, Kamijima Y, Sato T, et al. Epidemiology of psoriasis and palmoplantar pustulosis: a nationwide study using the Japanese national claims database. BMJ Open. 2015;5(1):e006450. https:// doi.org/10.1136/bmjopen-2014-006450.

68. Nair PA, Diwan NG, Singhal R, Vora RV. A prospective study of clinical profile in patients of palmoplantar dermatoses. Indian Dermatol Online J. 2017;8(5):331-5. https://doi.org/10.4103/idoj. IDOJ_308_16.

69. Pascoe VL, Kimball AB. Seasonal variation of acne and psoriasis: a 3-year study using the Physician Global Assessment severity scale. J Am Acad Dermatol. 2015;73(3):523-5. https://doi.org/10.1016/j. jaad.2015.06.001.

70. Touma Z, Eder L, Zisman D, et al. Seasonal variation in vitamin $\mathrm{D}$ levels in psoriatic arthritis patients from different latitudes and its association with clinical outcomes. Arthritis Care Res. 2011;63(10):1440-7.

71. Touma Z, Thavaneswaran A, Chandran V, Gladman DD. Does the change in season affect disease activity in patients with psoriatic arthritis? Ann Rheum Dis. 2012;71(8):1370-3. https://doi.org/10. 1136/annrheumdis-2011-201208.

72. Watad A, Azrielant S, Bragazzi NL, et al. Seasonality and autoimmune diseases: the contribution of the four seasons to the mosaic of autoimmunity. $\mathrm{J}$ Autoimmun. 2017;82:13-30. https://doi.org/10.1016/ j.jaut.2017.06.001.

73. Wu Y, Lin Y, Liu HJ, Huang CZ, Feng AP, Li JW. Childhood psoriasis: a study of 137 cases from central China. World J Pediatr. 2010;6(3):260-4. https://doi.org/10.1007/s12519-010-0213-0.

74. Patruno C, Ayala F, Megna M, Napolitano M, Balato N. Patient-physician relationship in patients with psoriasis. Indian J Dermatol Venereol Leprol. 2012;78(2):228. https://doi.org/10.4103/03786323.93657 .

75. Feldman SR, Fleischer AB Jr, Reboussin DM, et al. The self-administered psoriasis area and severity index is valid and reliable. J Invest Dermatol. 1996;106(1):183-6. 
76. Kitchen H, Cordingley L, Young H, Griffiths CE, Bundy C. Patient-reported outcome measures in psoriasis: the good, the bad and the missing! $\mathrm{Br} \mathrm{J}$ Dermatol. 2015;172(5):1210-21. https://doi.org/10. 1111/bjd.13691.

77. Feldman SR, Clark AR, Venkat AP, Fleischer AB Jr, Anderson RT, Rajagopalan R. The self-administered psoriasis area and severity index provides an objective measure of psoriasis severity. Br J Dermatol. 2005;152(2):382-3. https://doi.org/10.1111/j. 1365-2133.2005.06351.x.

78. Candido Dos Reis FJ, Lynn S, Ali HR, et al. Crowdsourcing the general public for large scale molecular pathology studies in cancer. EBioMedicine. 2015;2(7):681-9. https://doi.org/10.1016/j.ebiom. 2015.05.009.

79. Arthritis Power: A Creakyjoints Initiative. https:// arthritispower.creakyjoints.org. Accessed 6 Oct 2017.
80. Hattink B, Droes RM, Sikkes S, Oostra E, Lemstra AW. Evaluation of the Digital Alzheimer Center: testing usability and usefulness of an online portal for patients with dementia and their carers. JMIR Res Protoc. 2016;5(3):e144. https://doi.org/10. 2196/resprot.5040.

81. American Heart Association. PCORI and AHA partner to identify critical research needed to improve care for cardiovascular diseases: new initiative will crowdsource to fill evidence gaps related to highburden diseases. American Heart Association Newsroom. 2015. http://newsroom.heart.org/news/ pcori-and-aha-partner-to-identify-critical-researchneeded-to-improve-care-for-cardiovasculardiseases. Accessed 31 Aug 2017.

82. Kelman A, Robinson CO, Cochin E, et al. Communicating laboratory test results for rheumatoid factor: what do patients and physicians want? Patient Prefer Adherence. 2016;10:2501-17. https://doi. org/10.2147/ppa.s104396. 